\title{
Synthesis and Significance of Atrial Natriuretic Peptide: A Review
}

\section{ABSTRACT}

Unhealthy lifestyle habits lead to numerous diseases and among them heart diseases are predominant. Various factors play important role in heart diseases. Amongst such factors is Atrial Natriuretic Peptide (ANP) which tends to be significant. Though the discovery of ANP is the recent one, but its role in diagnosis of cardiovascular disease has taken fasttrack. In this context, authors have tried to review and summarise the current evidences and roles of ANP in cardiovascular diseases along with the focus on rising use of ANP in diagnosis and treatment of cardiovascular diseases. Hence, this is a brief account of discovery and biological actions of ANP, its synthesis and role as a biomarker.

\section{INTRODUCTION}

Cardiovascular diseases such as Myocardial Infarction (MI), heart failure, hypertrophic cardiomyopathy, coronary artery diseases and arrhythmias like atrial fibrillation are becoming more prevalent and have become one of the leading cause of death worldwide [1]. Current therapies to treat cardiovascular diseases have mainly targeted on the cardiovascular system and to a lesser extent to sympathetic nervous system. However, despite all the proven benefits of these treatments, the needs are still unmet in the proper treatment of cardiovascular diseases; therefore, there is a need for new therapeutic options to improve patient care.

After the discovery of ANP in December 1983 [1] and from the study conducted in 1984 [2], many advances have taken place to enhance the understanding of the pathophysiology of the heart. Prior to the discovery of ANP, the heart was believed to function solely for the transportation of blood to all organs in the body. After ANP was elucidated, it became clear that the heart also regulates blood pressure, electrolyte balance and fluid volume balance also $[3,4]$. Therefore, the heart plays at least two important biological roles: a pumping function and an endocrine function.

Amidst these biologically active substances, two molecules ANP and B-Type Natriuretic Peptide (BNP) are best recognised molecules, and are now-a-days clinically used as a diagnostic tool and also as therapeutic drugs in heart failure $[5,6]$.

The Ministry of Health and Welfare of Japan in 1995 permitted carperitide which is recombinant ANP for Intravenous (IV) injections to be used in patients with Acute Heart Failure (AHF) and Acutely Decompensated Heart Failure (ADHF) [7]. However, the other recombinant form of BNP (Nesiritide) was not approved for therapeutic use. But Food and Drug Administration of USA has approved Nesiritide in 2001. Therefore, the clinical evidences and major research for ANP has been compiled mainly in Japan, whereas the evidences and studies for BNP are mainly from the United States [7-9]. The outcome of their studies was that, Nesiritide significantly increases the risk of worsening renal function in patients with ADHF. In this context, authors have tried to review and summarise the current evidences and roles of ANP in cardiovascular diseases and then focussed on rising use of ANP in diagnosis and treatment of cardiovascular diseases.

Discovery of Atrial Natriuretic Peptide (ANP) From Natriuretic Peptide Family: ANP belongs to the family of Natriuretic peptide system. Natriuretic peptide system has a crucial role in our body like it acts as paracrine, autocrine and endocrine systems which help in balancing cardiovascular homeostasis. Natriuretic peptide system consists of three genetically different though structurally similar peptides that includes ANP, Brain Natriuretic Peptide (BNP), and C type Natriuretic Peptide (CNP) [4].

The discovery of atrial specific granules, which resembles the electron rich granules and is found inside the endocrine organs, was done by Kisch B in 1956 [10] which marked one of the first milestones on the path of ANP research. DeBold in 1979 found that the quantity of atrial-specific granules is decreased by water deprivation and increased by salt loading, which suggests that atrial specific granules may contain a biologically active substance involved in the activity of volume regulation [11]. Just at the end of 1983 and the beginning of 1984, a new peptide with 28 amino acid residues was isolated by deBold from rat atrial tissues [1] and by Matsuo and Kangawa from human atrial tissues [2]. This peptide was designated as ANP, and it exhibits diuretic, natriuretic, and vasodilating activities. The main site of synthesis of ANP is in the atria thus, ANP can be considered as cardiac hormone [12-14]. ANP inhibits Endothelin-1(ET-1) production which enhances natriuretic peptide synthesis. Changes in natriuretic peptide release were seen in many cardiovascular diseases.

\section{BIOLOGICAL ACTIONS OF ANP}

The ANP bind to the receptor, guanylylcyclase- A (GC-A), which is a membrane-type guanylylcyclase and it leads to biological actions through a cGMP-dependent pathway. ANP possess diuretic, natriuretic, and hypotensive activity. ANP triggers dilation of arteries and veins in an endothelium-independent manner. In vascular smooth muscle cells, GC-A is expressed abundantly; binding of ANP produces cGMP and activates cGMP-regulated protein kinase I (cGKI) [15]. Structural Maintenance of Chromosome (SMC) expresses both cGKl $\alpha$ and cGKI $\beta$. Earlier reports showed that CGKI inhibits vascular smooth muscle contraction by multiple mechanisms, including the $c G K / \beta /$ inositol 1,4,5-triphosphate-associated cGMP kinase substrate (IRAG), the cGKla/regulator of $\mathrm{G}$ protein signalling subtype2(RGS2) and the cGKla/ myosin light chain phosphatase (MLCP) signalling pathway. Inositol trisphosphate receptor-associated cGMP-kinase substrate signalling inhibits release of $\mathrm{Ca}++$ from sarcoplasmic reticulum (SR), cGKla binds, phosphorylates, and activates Regulator of G Protein Signaling 2 (RGS2), which terminates signalling by Gq-coupled receptors for contractile agonists [16]. Therefore, it is likely that cGKla/RGS2 signalling inhibits hormone receptor-triggered $\mathrm{Ca} 2+$ release and vasoconstriction. In the cGKl $\alpha / M L C P$ signalling pathway, cGKl $\alpha$ activates MLCP. When MLCP 
activity is increased, it reduces myosin light chain phosphorylation and causes its relaxation.

Thus, these are mechanisms of the acute depressor effect of ANP. However, in one such study by Sabrane Ket al., which was conducted on mice described that the mechanisms of the chronic depressor effect of ANP are quite dissimilar from those of acute effect [17]. They also concluded that the chronic depressor effect of ANP was found to be due to reduction in intravascular volume resulting from increased permeation of water and bit larger molecules through the endothelium into the interstitial space [Table/Fig-1] [17].

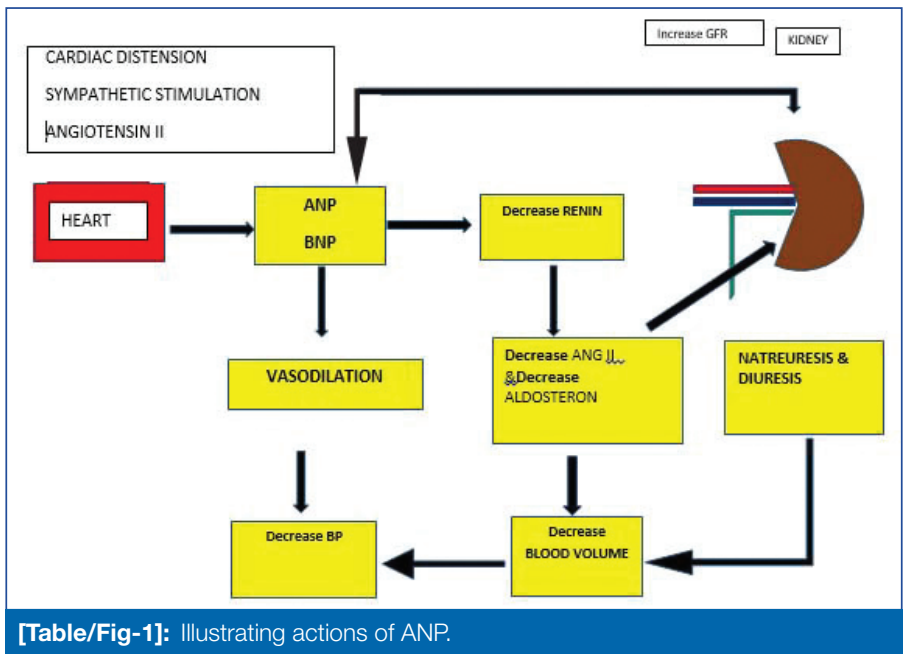

\section{ANP BIOSYNTHESIS AND PROCESSING}

ANP is synthesised and afterwards secreted by cardiac muscle cells in the walls of the atria of the heart. These ANP cells contain volume receptors which also respond in increasing and stretching of the atrial wall due to increased atrial blood volume. The total ANP concentration in the atrium of the human heart is increased in severe chronic heart failure. Due to the increase of small molecular weight forms of ANP i.e., beta-hANP, and alpha-hANP, specially betahANP. It indicates that the processing of ANP precursor, or gammahANP, in the human failing heart differs from that in the normal heart, suggesting that the failing heart supplements synthesis and secretion of ANP as one of its own compensatory responses [18]. Corin (type of Protein) is a type II transmembrane serine protease in large quantities expressed in the heart has been documented that that this Corin can convert pro-ANP to ANP, suggestive of Corin is likely a pro-ANP convertase [19].

\section{ANP as a Biomarker}

ANP plays an important role in regulating blood pressure, cardiac remodelling, Acute Myocardial Infarction (AMI), valve disease, heart failure and cardiac surgery.

\section{THERAPEUTIC USES OF ANP FOR CARDIOVASCULAR DISEASES}

Saito $Y$ et al., were the first to examine the effects of synthetic ANP on haemodynamics, renal excretory function, and hormone levels in patients with severe heart failure [20]. They concluded that infusion of ANP at a rate of $0.1 \mathrm{microgram} / \mathrm{kg} / \mathrm{min}$ decreased pulmonary capillary wedge pressure and increased stroke volume index in patients with heart failure which is a significant change. The ANP infusion also markedly increases the urine volume, excretion of sodium, and endogenous creatinine clearance, and decreased the aldosterone concentrations. These results indicates the possibility that ANP could be used as a therapeutic medicine in patients with heart failure [18]. The beneficial effects of natriuretic peptide may be applicable to AMI. One study was conducted to compare the effect of ANP with the effect of nitroglycerin (which is commonly used drug) on left ventricular remodelling after the first anterior AMI [21]. The development of left ventricular ejection fraction was greater in the group treated with ANP than in the nitroglycerin group, although the baseline appearances were similar between the two groups. Moreover, left ventricular expansion was prevented by ANP employment, but not so by nitroglycerin administration [21]. These findings suggested that ANP infusion can prevent left ventricular remodelling better than commonly used nitroglycerin in patients with AMI. Other investigators have also reported similar observations in their studies $[4,5,22,23]$. A prospective, randomised, and multicenter study was carried out in Japan to test whether acute infusion of ANP reduces myocardial infarct size or improves regional wall motion in AMI. They concluded that Japan-Working Groups of Acute Myocardial Infarction for the Reduction of Necrotic Damage by ANP (J-WINDANP)-ANP will provides important data on the effects of ANP as an adjunct to Percutaneous Coronary Intervention (PCI) for AMI and the Single Nucleotide Polymorphisms (SNPs) information will open the field of tailor-made therapy [23, 24].

\section{CONCLUSION(S)}

The synthesis, significance and therapeutics of ANP have been discussed here. Though its discovery is not very ancient one, but its potential in medical science cannot be ignored. It warrants so many more studies with larger sample sizes to elucidate importance of ANP in medical science.

\section{REFERENCES}

[1] De Bold AJ, Flynn TG. Cardionatrin I-a novel heart peptide with potent diuretic and natriuretic properties. Life Sciences. 1983;33(3):297-302.

[2] Kangawa K, Matsuo $\mathrm{H}$. Purification and complete amino acid sequence of $\alpha$-human atrial natriuretic polypeptide ( $\alpha$-hANP). Biochemical and Biophysical Research Communications. 1984.13;118(1):131-39.

[3] Nakao K, Ogawa Y, Suga SI, Imura H. Molecular biology and biochemistry of the natriuretic peptide system. I: Natriuretic peptides. Journal of Hypertension. 1992;10(9):907-12.

[4] Nakao K, Ogawa Y, Suga SI, Imura H. Molecular biology and biochemistry of the natriuretic peptide system. II: Natriuretic peptide receptors. Journal of Hypertension. 1992;10(10):1111-14.

[5] Schirone L, Forte M, Palmerio S, Yee D, Nocella C, Angelini F, et al. A review of the molecular mechanisms underlying the development and progression of cardiac remodeling. Oxidative Medicine and Cellular Longevity. 2017;2017:3920195.

[6] Weber M, Hamm C. Role of B-type natriuretic peptide (BNP) and NT-proBNP in clinical routine. Heart. 2006;92(6):843-49.

[7] Sackner-Bernstein JD, Skopicki HA, Aaronson KD. Risk of worsening renal function with nesiritide in patients with acutely decompensated heart failure. Circulation. 2005;111:1487-91.

[8] Dontas ID, Xanthos T, Dontas I, Lelovas P, Papadimitriou L. Impact of nesiritideon renal function and mortality in patients suffering from heart failure. Cardiovasc Drugs Ther. 2009;23:221-33.

[9] Mentzer Jr RM, Oz MC, Sladen RN, Graeve AH, Hebeler Jr RF, Luber Jr JM, et al. NAPA Investigators. Effects of periop-erativenesiritide in patients with left ventricular dysfunction undergoing cardiac surgery: The NAPA Trial. J Am Coll Cardiol. 2007;49:716-26.

[10] Kisch B. Electron microscopy of the atrium of the heart. Exp Med Surg. 1956:14:99-112.

[11] De Bold AJ. Heart atria granularity effects of changes in water-electrolyte balance. Proceedings of the Society for Experimental Biology and Medicine. 1979:161(4):508-11

[12] Saito $Y$, Nakao K, Itoh $H$, Yamada T, Mukoyama M, Arai $H$, et al. Brain natriuretic peptide is a novel cardiac hormone. Biochem Biophys Res Commun. 1989;158:360-68

[13] Mukoyama M, Nakao K, Hosoda K, Suga S, Saito Y, Ogawa Y, et al. Brain natriuretic peptide as a novel cardiac hormone in humans. Evidence for an exquisite dual natriuretic peptide system, atrial natri- uretic peptide and brain natriuretic peptide. J Clin Invest. 1991;87:1402-12.

[14] Ogawa Y, Nakao K, Mukoyama M, Shirakami G, Saito Y, Arai H, et al. Rat brain natriuretic peptide-Tissue distribution and molecular form. Endocrinology. 1990;126:2225-27.

[15] Hofmann F, Bernhard D, Lukowski R, Weinmeister P. cGMP regulated protein kinases(cGK): A textbook of cGMP: Generators, effectors and therapeutic implications. Verlag, Berlin, Heidelberg, Germany: Springer; 2009:137-162.

[16] Tang KM, Wang GR, Lu P, Karas RH, Aronovitz M, Heximer SP, et al. Regulator of G-protein signaling-2 mediates vascular smooth muscle relaxation and blood pressure. Nat Med. 2003;9:1506-12.

[17] Sabrane K, Kruse MN, Fabritz L, Zetsche B, Mitko D, Skryabin BV, et al. Vascular endothelium is critically involved in the hypotensive and hypovolemic actions of atrial natriuretic peptide. J Clin Invest. 2005:115(6):1666-74

[18] Pemberton CJ, Siriwardena M, Kleffmann T, Ruygrok P, Palmer SC, Yandle TG, et al. First identification of circulating prepro-A-type natriuretic peptide (preproANP) signal peptide fragments in humans: Initial assessment as cardiovascular biomarkers. Clin Chem. 2012;58:757-67. 
[19] Wu F, Yan W, Pan J, Morser J, Wu Q. Processing of pro-atrial natriuretic peptide by corin in cardiac myocytes. J Biol Chem. 2002;277(19):16900-05.

[20] Saito Y, Nakao K, Nishimura K, Sugawara A, Okumura K, Obata K, et al. Clinical application of atrial natriuretic polypeptide in patients with congestive heart failure: Beneficial effects on left ventricular function. Circulation. 1987;76:115-24.

[21] Hayashi M, Tsutamoto T, Wada A, Maeda K, Mabuchi N, Tsutsui T, et al. Intravenous atrial natriuretic peptide prevents left ventricular remodelling in patients with first anterior acute myocardial infarction. J Am Coll Cardiol. 2001;37:1820-26.

[22] Kuga H, Ogawa K, Oida A, Taguchi I, Nakatsugawa M, Hoshi T, et al. Administration of atrial natriuretic peptide attenuates reperfusion phenomena and preserves left ventricular regional wall motion after direct coronary angioplasty for acute myocardial infarction. Circ J. 2003;67:443-48.
[23] Asakura M, Jiyoong K, Minamino T, Shintani $Y$, Asanuma $H$, Kitakaze M, et al. Rationale and design of a large-scale trial using atrial natriuretic peptide (ANP) as an adjunct to percutaneous coronary intervention for ST-segment elevation acute myocardial infarction: Japan-Working groups of acute myocardia infarction for the reduction of Necrotic Damage by ANP (J-WIND-ANP). Circ J. 2004;68:95-100.

[24] Kitakaze M, Asakura M, Kim J, Shintani Y, Asanuma H, Hamasaki T, et al. J-WIND investigators. Human atrial natriuretic peptide and nicorandil as adjuncts to reperfusion treatment for acute myocardial infarction (J-WIND): Two randomised trials. Lancet. 2007;370(9597):1483-93.

\section{PARTICULARS OF CONTRIBUTORS:}

1. Associate Professor, Department of Anatomy, RVM Institute of Medical Science and Research, Laxmakapally, Mullugu, Siddipet, Hyderabad, Telangana, India.

2. Director Medical Research, Department of Pharmacology, Vinayaka Mission's Research Foundation-Deemed University, Vmrfdu, Chennai, Tamil Nadu, India.

3. Associate Professor, Department of Anatomy, Mahatma Gandhi Institute of Medical Sciences, Sevagram, Maharashtra, India.

4. Associate Non Interventional Clinical Cardiologists, Department of Cardiology, Virinchi Hospital, Hyderabad, India.

\section{NAME, ADDRESS, E-MAIL ID OF THE CORRESPONDING AUTHOR}

Shaikh Jasmeen,

Plot No. 20, Flat No. 501, Padmajalaya Apts, Near Blue Bells High School/Ratnadeep, Supermarket, Srinagar Colony, Hyderabad, Telangana, India.

E-mail: drshaikhjasmeen@gmail.com

\section{AUTHOR DECLARATION:}

- Financial or Other Competing Interests: None

- Was informed consent obtained from the subjects involved in the study? NA

- For any images presented appropriate consent has been obtained from the subjects.
PLAGIARISM CHECKING METHODS: [Jain H tet al.]

- Plagiarism X-checker: Sep 07, 2021

- Manual Googling: Dec 16, 2020

- iThenticate Software: Feb 23, 2021 (24\%)
ETYMOLOGY: Author Origin

Date of Submission: Aug 29, 2020 Date of Peer Review: Oct 05, 2020 Date of Acceptance: Dec 17, 2020

Date of Publishing: Jul 01, 2021 